\title{
Increased Prevalence of Precancerous Changes in Relatives of Gastric Cancer Patients: Critical Role of H. pylori
}

\author{
EMAD M. EL-OMAR,* KARIN OIEN,,$\S$ LILIAN S. MURRAY,* ADIL EL-NUJUMI,* ANGELA WIRZ,* \\ DEREK GILLEN,* CRAIG WILLIAMS," GRANT FULLARTON," and KENNETH E. L. MCCOLL* \\ Departments of * Medicine and Therapeutics, ‡Pathology, "Microbiology, and "Surgery, Western Infirmary; \\ and "CRC Department of Medical Oncology, § University of Glasgow, Glasgow, Scotland
}

See editorial on page 222.

Background \& Aims: Helicobacter pylori is believed to predispose to gastric cancer by inducing gastric atrophy and hypochlorhydria. First-degree relatives of patients with gastric cancer have an increased risk of developing gastric cancer. The aim of this study was to determine the prevalence of atrophy and hypochlorhydria and their association with $\mathrm{H}$. pylori infection in first-degree relatives of patients with gastric cancer. Methods: H. pylori status, gastric secretory function, and gastric histology were studied in 100 first-degree relatives of patients with noncardia gastric cancer and compared with those of controls with no family history of this cancer. Results: Compared with healthy controls, relatives of patients with gastric cancer had a higher prevalence of hypochlorhydria ( $27 \%$ vs. $3 \%$ ) but a similar prevalence of $\mathrm{H}$. pylori infection $(63 \%$ vs. $64 \%$ ). Relatives of cancer patients also had a higher prevalence of atrophy (34\%) than patients with nonulcer dyspepsia (5\%) matched for $\mathrm{H}$. pylori prevalence. Among the relatives of cancer patients, the prevalence of atrophy and hypochlorhydria was increased only in those with evidence of $\mathrm{H}$. pylori infection, was greater in relatives of patients with familial cancer than in relatives of sporadic cancer index patients, and increased with age. Eradication of $\mathrm{H}$. pylori infection produced resolution of the gastric inflammation in each subject and resolution of hypochlorhydria and atrophy in $50 \%$ of the subjects. Conclusions: Relatives of patients with gastric cancer have an increased prevalence of precancerous gastric abnormalities, but this increase is confined to those with $\mathrm{H}$. pylori infection. Consequently, prophylactic eradication of the infection should be offered to such subjects.

$\mathbf{G}$ astric cancer remains the second most common cause of cancer deaths on a world-wide basis. There is a well-recognized familial predisposition to the cancer, and the risk of developing it is greater in relatives of patients with familial cases of the cancer, in which more than 1 relative has been affected, than in relatives of sporadic index patients. ${ }^{1-5}$

$\mathrm{H}$ elicobacter pylori infection is present in $50 \%$ of the world's population, and infected subjects have an increased risk of developing cancer of the mid and distal stomach. ${ }^{6-9}$ The risk of developing gastric cancer is related to the histological and functional changes the infection induces in the stomach. ${ }^{10-14}$ In most $H$. pyl oriinfected subjects, the inflammation is largely confined to the antral mucosa and is accompanied by little if any atrophy. In subjects with this pattern of gastritis, gastric acid secretion is normal or increased. Such subjects have an increased risk of developing duodenal ulceration but little if any increased risk of gastric cancer. In other subjects, the inflammation involves the body region of the stomach to a degree similar to or greater than that seen in the antral region. This pangastritis and bodypredominant pattern of gastritis is usually accompanied by various degrees of atrophy and impairment of acidsecretory function. This latter subgroup of subjects with $H$. pyl ori-induced atrophic gastritis and hypochlorhydria has a markedly increased risk of noncardia gastric cancer. Gastric mucosal atrophy and hypochlorhydria are longrecognized cancer-associated abnormalities. ${ }^{15-21}$

Little is known about the role of $\mathrm{H}$. pyl ori infection as a risk factor for gastric cancer in subjects with a family history of this cancer. If the infection is intimately involved in the development of gastric cancer in these subjects, they provide an easily identified subgroup of infected subjects for prophylactic H. pylori eradication therapy.

W e examined the preval ence of atrophy and hypochlorhydria in first-degree relatives of patients with noncardia gastric cancer and the association between these precancerous abnormalities and $H$. pylori infection. We also

Abbreviations used in this paper: $\mathrm{Cl}$, confidence interval; NUD, nonulcer dyspepsia; PAO, peak acid output.

(C) 2000 by the American Gastroenterological Association 0016-5085/00/\$10.00 
examined the reversibility of these abnormalities by eradicating the infection.

\section{Subjects and Methods}

The overall design of the study involved examining $H$. pyl ori status, gastric secretory function, and gastric histol ogy in first-degree relatives of patients with noncardia gastric cancer. $\mathrm{H}$ ealthy volunteers were used as controls for the gastric secretory studies. In view of the ethical difficulties of performing endoscopy in a large number of heal thy vol unteers, patients with nonulcer dyspepsia (NUD) were used as controls for the histological study. The study was approved by the Western Infirmary Ethics Committee.

\section{Recruitment of First-Degree Relatives and Controls}

Case records of all patients with gastric cancer diagnosed in our hospital between 1991 and 1995 were examined, and all patients with documented, histopathologically proven noncardia gastric adenocarcinoma were identified. Surviving siblings or children of these index patients were invited to participate in the study. Relatives were excluded if either were younger than 18 or older than 75 years or had other serious medical problems.

One hundred first-degree rel atives of 40 gastric cancer index patients were recruited in this way (98 white, 2 Chinese). The maximum possible number of living and eligible relatives of the 40 index cases was 142. One hundred eighteen were contacted, but 13 declined to take part and 5 had serious medical problems.

The mean age of the 40 gastric cancer patients at the time of diagnosis was 67 years (range, 37-88 years). The histology of the 40 cancers showed intestinal type in 10, diffuse type in 17, and elements of both types in 8 . In the other 5 , details of the exact subtype were not available. The mean age of the 100 cancer relatives was 43.7 years (range, 20-67 years); 24 were siblings and 76 were children of the index patients. Of the 100 cancer relatives, 61 had only 1 relative known to have gastric cancer and 39 had more than 1 relative with the condition.

One hundred healthy subjects with no family history of gastric cancer were recruited as controls for the gastric acid secretion studies. Fifty of these were spouses of the cancer relatives, and the other 50 were recruited from the local population so that the control group was similar to the rel atives of cancer patients with respect to age, sex, body weight, and social class. The healthy controls were sel ected without knowledge of their $\mathrm{H}$. pyl ori status.

The control group for the histological study was obtained from patients who were concurrently undergoing upper gastrointestinal endoscopy for investigation of dyspepsia and had no evidence of esophagitis, ulcer disease, or cancer. Sixty of these patients with N UD and no family history of gastric cancer were selected to be similar to the first-degree relatives of cancer patients in age, sex, body weight, and social class. They were also sel ected to match the first-degree rel atives for preval ence of
H. pylori infection because of the recognized association between $H$. pylori infection and atrophic gastritis. These controls were selected without knowledge of histological status; H . pyl ori status was determined based on their ${ }^{14} \mathrm{C}$-urea breath and CLO tests.

\section{Assessment of Cancer Relatives, Healthy Controls, and NUD Controls}

All subjects underwent a ${ }^{14} \mathrm{C}$-urea breath test as described previously. ${ }^{22}$ Cancer relatives and heal thy controls underwent acid-secretory studies. Cancer relatives and NUD controls underwent upper gastrointestinal endoscopy to obtain gastric biopsy specimens and had blood taken for determination of $\mathrm{H}$. pylori immunoglobulin $(\mathrm{Ig}) \mathrm{G}$ serology as previously described. ${ }^{23}$ During endoscopic examination, biopsy specimens were obtained from the antral region within $2 \mathrm{~cm}$ of the pyloric ring and from the body region of the stomach between 50 and $55 \mathrm{~cm}$ along the greater curvature. A biopsy specimen from each sitewas used for the rapid urease sl idetest (CLO test; D el ta W est Pty. Ltd., Bentl ey, A ustral ia), 1 biopsy specimen was used for culture, and 3 biopsy specimens from each site were placed in 10\% formalin and submitted for histological examination.

\section{Assessment of Gastric Histology}

The antral and body biopsy specimens were embedded in paraffin, and $4-\mu \mathrm{m}$ sections were obtained. Sections at 3 levels were stained with $\mathrm{H} \& \mathrm{E}$ and assessed for the parameters discussed below. Onesection was stained using cresyl fast viol et for assessment of $\mathrm{H}$. pylori colonization. In equivocal cases, immunohistochemistry was used to confirm the presence or absence of $\mathrm{H}$. pylori organisms. The biopsy specimens were scored blindly without knowledge of diagnosis or acid output. All histological analyses were performed by 1 observer (K.O.). Five morphol ogical parameters were assessed using the Sydney system ${ }^{24-27}$ and graded from 0 to $3(0$, none; 1 , mild; 2 , moderate; 3 , severe). The 5 parameters were (1) inflammation, which scored the chronic inflammatory infiltrate in the lamina propria; (2) activity, which scored the acute inflammatory infiltrate; (3) atrophy, which was scored on the basis of the presence and proportion of glandular loss 24,25 ; (4) intestinal metaplasia, scored as absent or occupying less than one third, more than one third, or more than two thirds of the mucosa present; and (5) density of $\mathrm{H}$. pyl ori colonization. Inflammation and activity scores ( 1 and 2 ) were added together for a combined (acute and chronic) inflammatory score with a maximum possible score of 6 .

\section{Assessment of Gastric Acid Secretion}

Peak acid output (PAOPG) was assessed in response to pentagastrin (Peptavl on; ICl, Cheshire, England) infused intravenously at a rate of $0.6 \mu \mathrm{g} \cdot \mathrm{kg}^{-1} \cdot \mathrm{h}^{-1}$ for 1 hour as described previously. ${ }^{14}$ 
Assessment of $\mathrm{H}$. pylori Status in Cancer

Relatives and Healthy Controls

In relatives of cancer patients, $H$. pylori status was considered positive if results of 2 or more of the 5 tests were positive. In the healthy controls, $\mathrm{H}$. pyl ori status was based on results of the ${ }^{14} \mathrm{C}$-breath test, which we have shown to have a sensitivity of $98 \%$ and specificity of $100 \%$ using histology plus the urease slide test as a gold standard. ${ }^{22}$

\section{Eradication of H. pylori}

After assessment, all $\mathrm{H}$. pylori-positive cancer relatives received $H$. pyl ori eradication therapy in the form of a 1-week course of omeprazole, $20 \mathrm{mg}$ twice daily; amoxicillin, $500 \mathrm{mg}$ 3 times daily; and clarithromycin, 500 mg 3 times daily. For infected cancer relatives with hypochlorhydria, metronidazole, $400 \mathrm{mg} 3$ times daily, instead of omeprazole was used. Six weeks after this treatment, a ${ }^{14} \mathrm{C}$-urea breath test was performed to assess success of eradication. In those in whom the initial eradication regimen failed, a 2-week course of clarithromycin, 500 mg 3 times daily; amoxicillin, 500 mg 3 times daily; and either tripotassium dicitratobismuthate (Denol), 120 mg 3 times daily, or metronidazole, 400 mg 3 times daily, was given. Patients were reassessed as described above. All cancer relatives were invited back 11 months after eradication assessment to undergo posteradication studies.

\section{Statistical Analysis}

Comparison of medians in the different groups was made using the K ruskal-Wallis test. Pairwise comparisons were made using a $M$ ann-W hitney test and confidence interval. W hen multiple comparisons were made after a significant $K$ ruskal-Wallis test result, confidence intervals and $P$ values were corrected using the Bonferroni method. Preval ence rates were compared using a $\chi^{2}$ test. For those with a 1-year follow-up, the change in scores was analyzed using a W ilcoxon signed-rank test and confidence interval $(\mathrm{Cl})$, and the changein prevalence rate was assessed using the $\mathrm{McN}$ emar test. Risk factors for hypochlorhydria and atrophy were determined using stepwise logistic regression. The computing packages SPSS and M initab were used for data anal ysis. All tests were 2-sided.

\section{Results}

\section{H. pylori Infection}

The prevalence $(95 \% \mathrm{Cl})$ of $\mathrm{H}$. pyl ori infection was $63 \%(53 \%-72 \%)$ in cancer relatives and $64 \%(54 \%-$ $73 \%$ ) in healthy controls. In all $63 \mathrm{H}$. pylori-positive relatives of cancer patients, infection was eradicated successfully after 1 or 2 courses (9 subjects) of treatment. Forty-three relatives of cancer patients agreed to repeat all tests 1 year after eradication of the infection; of these, 40 remained $\mathrm{H}$. pyl ori-negative at that time.

\section{Endoscopic Abnormalities}

Of the $63 \mathrm{H}$. pylori-positive relatives of cancer patients, $8(13 \%)$ were found to have peptic ulcers (5 duodenal, 2 prepyloric, and 1 both). Only 3 of the 8 subjects with ulcers had ever experienced any dyspeptic symptoms, and none were receiving antiulcer medication. In addition to the 8 subjects with ulcers, 6 other subjects had small hiatus hernias and 2 had grade 1 esophagitis. $\mathrm{N}$ one of the $37 \mathrm{H}$. pyl ori-negative cancer relatives had any significant endoscopic abnormalities apart from 4 subjects who had small hiatus hernias.

\section{Acid-Secretory Status of Cancer Relatives Versus Healthy Controls}

The individual acid outputs and $\mathrm{H}$. pylori status for cancer relatives and heal thy controls are shown in Figure 1. The median values of acid output in the 4 groups were significantly different $(P \leq 0.001)$. Pairwise comparison of the $\mathrm{H}$. pyl ori-positive cancer relatives with $\mathrm{H}$. pyl ori-positive controls showed that the median value for the former was significantly lower than that for the latter $(\mathrm{P} \leq 0.001 ; 95 \% \mathrm{Cl}$ for difference in medians, 7-14 $\mathrm{mmol} / \mathrm{h}$ ). There was no evidence of a difference between $\mathrm{H}$. pyl ori-negative cancer rel atives and $\mathrm{H}$. pyl orinegative controls ( $\mathrm{P}=0.39 ; 95 \% \mathrm{Cl},-2$ to $6 \mathrm{mmol} / \mathrm{h}$ ).

The preval ence of hypochlorhydria in cancer relatives (i.e., PAO $\mathrm{PG}_{\mathrm{P}}<15 \mathrm{mmol} / \mathrm{h}$ ) was $27 \%$, compared with $3 \%$ in the heal thy controls $(95 \% \mathrm{Cl}$ for difference in prevalence in these 2 groups, $15 \%-33 \%$; $P<0.001)$. This high prevalence of hypochlorhydria in cancer relatives was attributable to its high prevalence in $\mathrm{H}$. pyloripositive cancer relatives $(40 \%)$ compared with that in

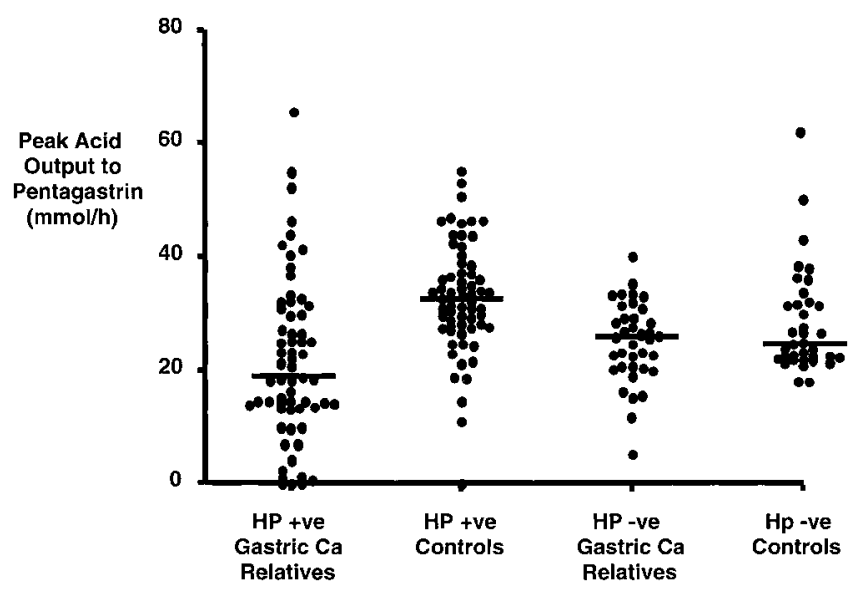

Figure 1. Individual PAO values in H. pylori (HP)-positive and -negative first-degree relatives of gastric cancer patients and controls. Median values are shown by horizontal bars. The median acid output of HP-positive relatives of cancer patients is lower than that of HPpositive controls $(P<0.001)$. The median acid output of HP-negative relatives of cancer patients is not different from that of HP-negative controls $(P=0.39)$. 
$\mathrm{H}$. pylori-negative cancer relatives $(5 \%)(95 \% \mathrm{Cl}$ for difference in prevalence rates, $20 \%-48 \% ; P \leq 0.001$ ). Few $H$. pylori-positive controls $(5 \%)$ and no $H$. pylorinegative controls had hypochl orhydria.

In $\mathrm{H}$. pylori-positive cancer relatives, the median $P A O_{P G}$ in the 8 subjects with ulcers was $39.1 \mathrm{mmol} / \mathrm{h}$, which was significantly higher than the median (18.1 $\mathrm{mmol} / \mathrm{h}$ ) for those without ulcers ( $\mathrm{P}<0.001 ; 95 \% \mathrm{Cl}$ for difference in medians in ulcer and nonulcer groups, 12-30 $\mathrm{mmol} / \mathrm{h}$ ). The individual acid output values are shown in Figure 1.

A logistic regression analysis was performed in cancer relatives to determine risk factors for hypochlorhydria. Age, H. pylori status, duodenal ulcer, relationship to cancer patient (offspring or sibling), gender, whether the relative with cancer had familial cancer or was a sporadic index case, and position among siblings within the family were considered potential risk factors. In a stepwise analysis, only age $(P<0.001), H$. pylori status $(P=$ $0.01)$, and whether the cancer was familial or a sporadic index case ( $P=0.02$ ) were significant predictors of hypochlorhydria.

One year after eradication of $\mathrm{H}$. pylori, the median $P A O_{P G}$ in the 40 of $63 \mathrm{H}$. pylori-positive cancer relatives who were studied increased from $15.3 \mathrm{mmol} / \mathrm{h}$ (range, 0-46.1 $\mathrm{mmol} / \mathrm{h}$ ) to $21.6 \mathrm{mmol} / \mathrm{h}$ (range, $0.6-50 \mathrm{mmol} / \mathrm{h}$ ). The $95 \% \mathrm{Cl}$ for the median increase was $1.7-5.5 \mathrm{mmol} / \mathrm{h}$ $(P=0.004)$. The increase in acid output was caused by the increase in the 20 who were hypochlorhydric at presentation; their median acid output increased from 9.8 $\mathrm{mmol} / \mathrm{h}$ (range, 0-14.6 $\mathrm{mmol} / \mathrm{h}$ ) to $16.1 \mathrm{mmol} / \mathrm{h}$ (range, 0.6-24 mmol/h) 1 year after eradication. The $95 \% \mathrm{Cl}$ for the median increase was 3.7-9.0 $\mathrm{mmol} / \mathrm{h}(P<0.001)$ (Figure 2). Of the 20 subjects who were hypochlorhydric
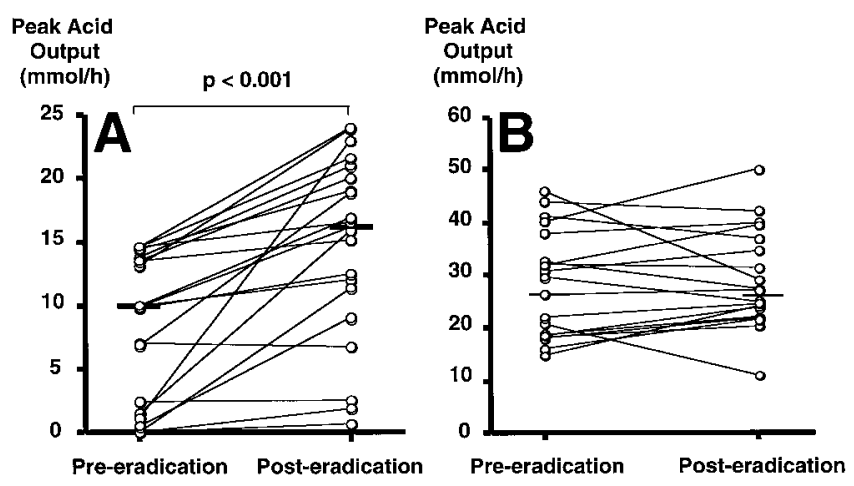

Figure 2. Effect of eradication of $H$. pylori infection on PAO in response to pentagastrin in $H$. pylori-positive cancer relatives who $(A)$ were and $(B)$ were not hypochlorhydric (PAO $<15 \mathrm{mmol} / \mathrm{h}$ ) on initial presentation. Acid secretion was reassessed 1 year after eradication of $H$. pylori. Note that the scale of the $y$ axis is different in the 2 figures. Median values are shown by horizontal bars. before treatment, $50 \%$ had restoration of normal levels of acid secretion after eradication of the infection.

\section{Gastric Histology in Cancer Relatives Compared With NUD Controls}

Combined inflammatory score. The median antral combined inflammatory score in the $63 \mathrm{H}$. pyloripositive cancer relatives was 5 (range, $0-6)$, which was similar to that in the $\mathrm{H}$. pylori-positive NUD controls (median, 4.5; range, $0-6 ; P=0.78$ ). Both were significantly higher than the median in $\mathrm{H}$. pylori-negative cancer relatives (median, 0 ; range, $0-2$; both $\mathrm{P}<0.001$ ) or $H$. pylori-negative NUD controls (median, 1 ; range, 0 -3; both $\mathrm{P}<0.001$ ). The median body inflammatory score in the $63 \mathrm{H}$. pylori-positive cancer relatives was 3 (range, 0-6), which was higher than the median for the $H$. pyl ori-positive N UD controls (median, 2; range, $0-5$; $P=0.03$ ). Scores in both $\mathrm{H}$. pyl ori-positive groups were significantly higher than the median for the $\mathrm{H}$. pylorinegative cancer relatives (median, 1 ; range, $0-1$; both $\mathrm{P}<0.001$ ) or $\mathrm{H}$. pyl ori-negative N U D controls (median, 1 ; range, $0-2$; both $P<0.001$ ).

One year after eradication of $\mathrm{H}$. pyl ori infection, in the 40 cancer relatives who remained infection free, both the median antral and body inflammatory scores decreased from 4 to 1 . The $95 \% \mathrm{Cls}$ for the median decrease in antral and body inflammatory scores were 2.5-3.0 ( $P<$ $0.001)$ and $2.0-3.0$, respectively $(P<0.001)$.

A trophy. The prevalence of atrophy of antrum and/or body mucosa in the 100 cancer relatives was 34\%, which was significantly higher $(P<0.001)$ than the $5 \%$ preval ence in NUD patients. The increased prevalence of atrophy in the cancer relatives was caused by a high prevalence of atrophy $(52 \%)$ in the $\mathrm{H}$. pylori-positive cancer relatives, compared with a preval ence of $3 \%$ in $\mathrm{H}$. pylori-negative cancer relatives, $5 \%$ in $\mathrm{H}$. pylori-negative NUDs, and $5 \%$ in $\mathrm{H}$. pylori-positive N UDs.

The severity and distribution of atrophy within the stomach are shown in Table 1 . Of the $33 \mathrm{H}$. pyloripositive cancer relatives with atrophy, it was of grade 1 severity in 24, grade 2 severity in 8 , and grade 3 severity in 2. The atrophy affected only the antral region in 9, only the body region in 14, and both the antral and body regions in 10 subjects.

Logistic regression analysis was performed to identify risk factors for atrophy in the cancer relatives as before. In addition to $H$. pylori status ( $P=0.002)$, only age $(P<$ 0.001 ) and whether the relative's cancer was a familial or sporadic index case ( $\mathrm{P}=0.02)$ predicted atrophy.

One year after eradication of $\mathrm{H}$. pylori infection, the preval ence of atrophy decreased from $63 \%$ to $38 \%$ ( $P<$ 0.002 ). This was mainly caused by resolution in those 
Table 1. Prevalence and Severity of Atrophy and Intestinal Metaplasia of Antrum and Body of Stomach in $\mathrm{H}$. pylori-Positive and -Negative Relatives of Patients With Gastric Cancer and Controls With NUD

\begin{tabular}{|c|c|c|c|c|}
\hline & \multicolumn{2}{|c|}{$\begin{array}{c}\text { Cancer patients' } \\
\text { relatives }\end{array}$} & \multicolumn{2}{|c|}{ NUD controls } \\
\hline & $\begin{array}{c}\text { H. pylori }+ \\
(n=63)\end{array}$ & $\begin{array}{c}\text { H. pylori - } \\
(\mathrm{n}=37)\end{array}$ & $\begin{array}{l}\text { H. pylori }+ \\
(\mathrm{n}=40)\end{array}$ & $\begin{array}{c}\text { H. pylori- } \\
(\mathrm{n}=20)\end{array}$ \\
\hline \multicolumn{5}{|l|}{ Atrophy } \\
\hline Antrum alone & $9(14 \%)$ & $0(0 \%)$ & $1(2.5 \%)$ & $0(0 \%)$ \\
\hline Grade $1-2-3^{a}$ & $6-3-0$ & & $1-0-0$ & \\
\hline Body alone & $14(22 \%)$ & $0(0 \%)$ & $1(2.5 \%)$ & $1(5 \%)$ \\
\hline Grade $1-2-3^{a}$ & $11-2-1$ & & $1-0-0$ & $0-1-0$ \\
\hline Both (antrum, body) & $10(16 \%)$ & $1(3 \%)$ & $0(0 \%)$ & $0(0 \%)$ \\
\hline \multicolumn{5}{|c|}{ Grade $(1,1)-(1,2)-$} \\
\hline$(2,1)-(2,2)^{b}$ & $7-1-1-1$ & $0-0-0-1$ & & \\
\hline Either (any) & $33(52 \%)$ & $1(3 \%)$ & $2(5 \%)$ & $1(5 \%)$ \\
\hline \multicolumn{5}{|l|}{ Intestinal metaplasia } \\
\hline Antrum alone & $11(17 \%)$ & $1(3 \%)$ & $6(15 \%)$ & $0(0 \%)$ \\
\hline Grade $1-2-3^{a}$ & $6-5-0$ & $0-1-0$ & $6-0-0$ & \\
\hline Body alone & $2(3 \%)$ & $0(0 \%)$ & $0(0 \%)$ & $1(5 \%)$ \\
\hline Grade $1-2-3^{a}$ & $1-1-0$ & & & $1-0-0$ \\
\hline Both (antrum, body) & $4(6 \%)$ & $1(3 \%)$ & $0(0 \%)$ & $0(0 \%)$ \\
\hline \multicolumn{5}{|l|}{ Grade $(1,1)-(1,2)$ - } \\
\hline$(2,2)-(3,3)^{b}$ & $1-1-2-0$ & $0-0-0-1$ & & \\
\hline Either (any) & 17 (27\%) & $2(6 \%)$ & $6(15 \%)$ & $1(5 \%)$ \\
\hline
\end{tabular}

aNumber of subjects in the 3 different categories of severity of atrophy (eg, 6-3-0 indicates 6 subjects with grade 1,3 with grade 2 , and 0 with grade 3 ).

${ }^{b}$ Number of subjects with the different combinations of severity of atrophy of both antrum and body (eg, 7-1-1-1 indicates 7 subjects with antrum grade 1 and body grade 1, 1 subject with antrum grade 1 and body grade 2, 1 subject with antrum grade 2 and body grade 1 , and 1 subject with antrum grade 2 and body grade 2 ).

with mild degrees of atrophy before treatment (Table 2). Of the 25 subjects with atrophy at presentation, resolution of normal mucosal appearance was achieved in 12 after eradication of the infection.

Intestinal metaplasia. The prevalence of intestinal metaplasia in the antrum and/or body mucosa was $19 \%$ in cancer relatives and $12 \%$ in N UD controls ( $P=0.22$ ). In both groups, the prevalence of intestinal metaplasia

Table 2. Atrophy Score at First Examination and After 1 Year of Follow-up in 40 Cases in Which Infection Was Eradicated

\begin{tabular}{crccccccccc}
\hline $\begin{array}{c}\text { Atrophy (antrum, } \\
\text { body) score } \\
\text { at first examination }\end{array}$ & 0,0 & 0,1 & 0,2 & 1,0 & 1,1 & 1,3 & 2,0 & 2,2 & Total \\
\cline { 2 - 9 } & 14 & 1 & 0 & 0 & 0 & 0 & 0 & 0 & 15 \\
0,0 & 5 & 1 & 1 & 0 & 0 & 0 & 1 & 0 & 8 \\
0,1 & 1 & 0 & 0 & 0 & 0 & 1 & 0 & 0 & 2 \\
0,2 & 0 & 0 & 1 & 0 & 0 & 0 & 0 & 0 & 1 \\
0,3 & 3 & 1 & 0 & 0 & 1 & 0 & 0 & 0 & 5 \\
1,0 & 2 & 0 & 0 & 1 & 2 & 0 & 0 & 0 & 5 \\
1,1 & 1 & 0 & 0 & 0 & 0 & 0 & 0 & 0 & 1 \\
1,2 & 0 & 0 & 0 & 1 & 0 & 0 & 1 & 0 & 2 \\
2,0 & 0 & 0 & 0 & 0 & 0 & 0 & 0 & 1 & 1 \\
2,2 & 26 & 3 & 2 & 2 & 3 & 1 & 2 & 1 & 40 \\
Total & & & & & & & &
\end{tabular}

was higher in those with evidence of $H$. pylori infection (Table 1).

O ne year after eradication of $\mathrm{H}$. pyl ori infection, there was no overall change $(P=0.2)$ in the degree of intestinal metaplasia in the 40 cancer rel atives who were studied.

Association Between Gastric Secretory

Function and Gastric Histology in

H. pylori-Positive Cancer Relatives

In H . pylori-positive cancer relatives, there was an association between the presence of hypochlorhydria and atrophy (Table 3). A trophy was present in $84 \%$ of the hypochlorhydric subjects and only $32 \%$ of those without hypochlorhydria ( $\mathrm{P} \leq 0.001)$. The hypochlorhydric subjects also had evidence of more severe body gastritis than the normochlorhydric subjects (median scores of 4 and 2 , respectively; $P \leq 0.001$ ), and a higher prevalence of pangastritis or body-predominant distribution of gastritis (44\% vs. $5 \%$; $P \leq 0.001$ ). In addition, a higher proportion of the hypochlorhydric subjects had bodypredominant $\mathrm{H}$. pylori colonization (36\% vs. $13 \%$; P $\leq$ 0.04).

\section{Discussion}

This study indicates that relatives of patients with noncardia gastric cancer have an increased prevalence of gastric atrophy and hypochlorhydria. The prevalence of hypochlorhydria was $27 \%$ in cancer relatives compared with $3 \%$ in controls, and that of atrophy was 34\% compared with $5 \%$ in controls. Our findings of increased prevalence of atrophic gastritis and hypochlorhydria in relatives of gastric cancer patients are consistent with findings of previous studies ${ }^{28-31}$ and supports a role for these abnormalities in the sequence of events leading to noncardia gastric cancer.

In the present study, we were able to extend previous work by demonstrating that the precancerous abnormalities prevalent in relatives of patients with cancer were confined almost entirely to $\mathrm{H}$. pylori-infected subjects (Figure 3). The prevalence of atrophy in the cancer relatives with $\mathrm{H}$. pylori infection was $52 \%$, compared with $3 \%$ in those without $H$. pylori infection. Likewise, the prevalence of hypochlorhydria was $40 \%$ in the $\mathrm{H}$. pylori-positive cancer relatives and 5\% (2 subjects) in those not infected. The association between $\mathrm{H}$. pylori infection and these precancerous abnormalities may be even stronger because of the likelihood that the $2 \mathrm{H}$. pylori-negative subjects with gastric abnormalities had been infected at some time. One of these 2 patients had atrophy and hypochlorhydria and came from a family of 10 siblings. All of the 4 surviving siblings had evidence 
Table 3. Comparison of Gastric Mucosa His tology in H. pylori-Positive Cancer Relatives With and Without Hypochlorhydria $(\mathrm{PAO}<15 \mathrm{mmol} / \mathrm{h})$

\begin{tabular}{|c|c|c|c|c|}
\hline & $\begin{array}{l}\text { Normochlorhydric } \\
\qquad(\mathrm{n}=38)\end{array}$ & $\begin{array}{l}\text { Hypochlorhydric } \\
\quad(n=25)\end{array}$ & $\begin{array}{c}95 \% \mathrm{Cl} \text { for difference } \\
\text { between groups }\end{array}$ & $P$ \\
\hline Prevalence of atrophy & $12(32 \%)$ & $21(84 \%)$ & $32 \%-73 \%$ & $<0.001$ \\
\hline Severity of body gastritis ${ }^{a}$ & $2(0-6)^{c}$ & $4(1-6)^{c}$ & $0.9-2.5$ & $<0.001$ \\
\hline Severity of antral gastritis ${ }^{a}$ & $5(2-6)^{c}$ & $4(0-6)^{c}$ & $-0.0-1.0$ & 0.24 \\
\hline Prevalence of pangastritis plus body-predominant gastritis ${ }^{b}$ & $2(5 \%)$ & $11(44 \%)$ & $18 \%-59 \%$ & $<0.001$ \\
\hline Prevalence of $H$. pylori colonization density greater in body than antrum & $5(13 \%)$ & $9(36 \%)$ & $12 \%-45 \%$ & $<0.04$ \\
\hline
\end{tabular}

aCombined inflammatory score (i.e., acute + chronic inflammatory cell infiltrate).

bS ubjects in whom the combined inflammatory score of the body region was equal to or greater than that of the antral region.

cMedian (range).

of $\mathrm{H}$. pylori infection, and 2 siblings who died of gastric cancer also had documented evidence of $\mathrm{H}$. pylori infection. Therefore, it is likely that this subject had been infected and that the infection had disappeared after its induction of atrophy and achlorhydria. The only other $\mathrm{H}$. pylori-negative patient with hypochlorhydria (PAOPG, 11.8 ) is a 67-year-old missionary who had worked in remote regions of Africa for much of his life. He had taken many antibiotics, including metronidazole, during his stay in A frica. It is likely that this subject al so had the infection, and it was eradicated by antibiotic treatment. W hen other evidence of probable previous infection is taken into account, it appears that atrophy and hypochlorhydria might be entirely confined to cancer relatives with current or previous $\mathrm{H}$. pylori infection.

A mong the $\mathrm{H}$. pylori-infected cancer relatives, there was a positive close correlation of the presence of hypochlorhydria and atrophy. In addition, those with hypochlorhydria had more severe inflammation of the

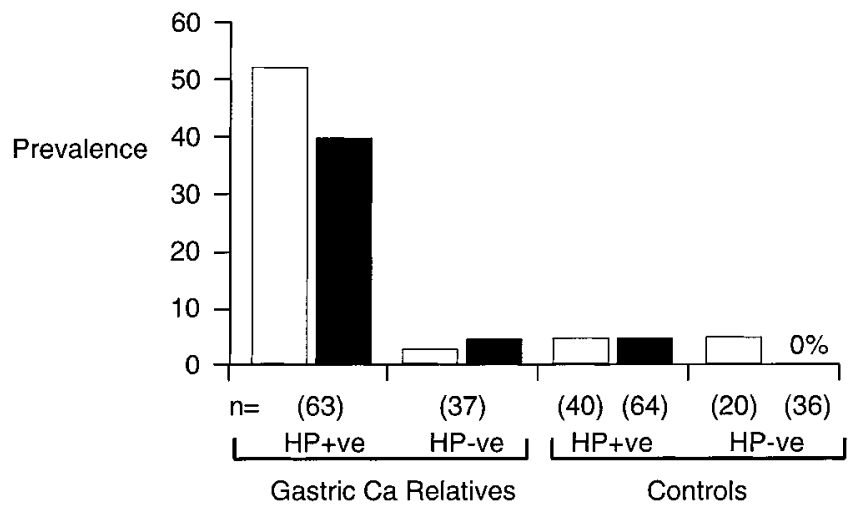

Figure 3. Prevalence of gastric atrophy ( $\square$ ) and hypochlorhydria ( $\square$ ) in first-degree relatives of gastric cancer patients and controls, both grouped according to $\mathrm{H}$. pylori (HP) status. Numbers of subjects are indicated in parentheses at the foot of each column. The controls for prevalence of hypochlorhydria consisted of 50 spouses of the cancer relatives and 50 volunteers matched for age, sex, body weight, and social class. The controls for prevalence of atrophy consisted of patients with NUD matched for age, sex, social class, and prevalence of HP infection. body region of their stomach. The hypochlorhydric subjects also had a more body-predominant distribution of $H$. pylori colonization and a much higher preval ence of a body-predominant or pangastritis distribution of the inflammation. We have previously reported that a subgroup of $H$. pylori-infected subjects develop this functional and histological response to the infection and postulated that those subjects are the ones most likely to progress to gastric cancer. ${ }^{14}$

The histological diagnosis of atrophy is generally recognized to be difficult, particularly when the process is in its early stage. Gastric acid secretion is a much more quantifiable entity, and reduction in gastric acid output correlates with both atrophy and the $\mathrm{H}$. pyl ori-associated pattern of gastritis progressing to atrophy. Combined assessment of gastric function and gastric histology is thus very useful in obtaining a reliable assessment of the overall state of the gastric mucosa.

The mean age of gastric cancer rel atives at examination was 23 years lower than the age of the cancer index cases at diagnosis. Consequently, examination of the relatives provides insight into changes in the gastric mucosa that occurred many years before the devel opment of the cancer itself. Our findings that atrophy and hypochlorhydria are more preval ent in cancer relatives support a role for these abnormalities in the sequence of events leading to the cancer. In addition, that these abnormalities are almost entirely confined to $\mathrm{H}$. pylori-positive subjects supports the role of the infection in their pathogenesis. Together, these observations provide strong evidence that the infection plays an important role in the pathogenesis of gastric cancer.

The increased preval ence of atrophy and hypochlorhydria in the cancer relatives was not explained by any increased prevalence of $H$. pylori infection. Rather, it appeared to be the result of an increased propensity to develop atrophy and hypochlorhydria in response to infection. Several mechanisms could explain this. It could 
be caused by particularly virulent strains of the infection that could be transmitted between family members. The best bacterial marker of increased pathogenic virulence is the presence of the CagA pathogenic island. ${ }^{32} \mathrm{H}$ owever, more than $50 \%$ of our infected general population and NUD patients have this strain, and even an increased preval ence of $100 \%$ CagA positivity in the gastric cancer relatives would beinsufficient to account for the degree of increased preval ence of precancerous abnormalities. Other bacterial virulence factors may be important. ${ }^{33}$

$\mathrm{H}$ ost genetic factors may be important in determining the response to $\mathrm{H}$. pylori infection; this possibility is supported by our finding that the prevalence of atrophy and hypochlorhydria was greater in relatives of patients with familial cancer than in relatives of sporadic index patients. Azuma et al. ${ }^{34}$ recently reported that absence of the DQA $1 * 0102$ allele may confer susceptibility to atrophy and gastric adenocarcinoma in $\mathrm{H}$. pyl ori-infected subjects.

It has been proposed that the host's premorbid acidsecretory status influences the outcome of the infection. ${ }^{35}$ $\mathrm{H}$ igh acid secretion confines the gastritis to the antrum, whereas low acid secretion al lows devel opment of pangastritis. $^{36,37}$ We were able to test this hypothesis by comparing the acid-secretory status of the uninfected gastric cancer relatives with that of uninfected controls. Acid output in these 2 groups was the same, thus providing no evidence that premorbid familial acid hyposecretion explains the increased tendency to have an abnormal response to $\mathrm{H}$. pylori infection in relatives of patients with gastric cancer.

Environmental factors in early life, such as deficiency of dietary antioxidants, might influence responses to $\mathrm{H}$. pyl ori infection. ${ }^{38} \mathrm{H}$ owever, we found that the preval ence of precancerous abnormalities was similar in offspring and siblings, although siblings had childhoods more similar to those of the index cancer patients.

It is probably naive to presume that a single entity will explain why some people develop hypochlorhydria and atrophy in response to $\mathrm{H}$. pyl ori infection. It is morelikely that the response is caused by the combined effects of bacterial pathogenicity, dietary antioxidant deficiency, and the nature of the host's genetically determined immune response to the organism. Our current family studies certainly point toward a significant role for host genetics.

Logistic regression analysis showed that the age of the subjects was a strong predictor of the likelihood of precancerous abnormalities in $\mathrm{H}$. pylori-positive cancer relatives. It is unclear to what extent the association with age is attributable to progressive development of the abnormalities as the subjects grow ol der or a cohort effect related to environmental or dietary conditions in previous years.

O ne of the unexpected findings in our study was the high prevalence $(13 \%)$ of previously unrecognized peptic ulcers in $\mathrm{H}$. pylori-positive cancer relatives. Five of the 8 patients with ulcers were completely asymptomatic, and the others reported a history of only mild dyspepsia for which no medical advice had been sought. Two previous European studies of the H . pylori-positivegeneral population have found a high prevalence of ulcers at endoscopy ( $14 \%$ and $21 \%$ ); most of these ulcers were asymptomatic. $^{39,40}$

In the present study, we al so investigated the effect of eradication of $\mathrm{H}$. pylori infection on the histological and functional abnormalities involved in the carcinogenic cascade. Eradication of the infection resulted in complete resolution of inflammation and partial resolution of both hypochlorhydria and atrophy. One year after eradication of the infection, a normal level of acid secretion was restored in $50 \%$ of those who had been hypochlorhydric, and there was no evidence of atrophy in $48 \%$ of those with atrophy at presentation. The resolution of atrophy was confined to those with grade 1 severity of atrophy at presentation.

In summary, we found that relatives of patients with noncardia gastric cancer have an increased prevalence of hypochlorhydria and atrophy and that these precancerous abnormalities are almost entirely confined to subjects with $\mathrm{H}$. pyl ori infection. These findings indicate a critical role of $\mathrm{H}$. pylori infection in the process of events leading to noncardia gastric cancer in subjects with a family history of this tumor.

Our findings raise an important clinical and public health issue. Should subjects with a family history of noncardia gastric cancer be routinely screened for $\mathrm{H}$. pylori infection and treated if it is present? The answer to this question depends on the effectiveness of such treatment in prevention of cancer devel opment. Treatment of $H$. pylori infection resolves the inflammatory gastritis in all cases and restores normal structure and secretory function to approximately $50 \%$ of those with hypochlorhydria and atrophy before treatment. This is likely to at least reduce the risk of progression to cancer. Because resolution of atrophy was seen only in those with grade 1 severity, eradication of the infection at an early stage in the disease process is likely to be important.

The appropriateness of prophylactic treatment for any condition also depends on the acceptability of the treatment and the gravity of the condition one is trying to prevent. H. pylori eradication therapy is inexpensive 
and safe, whereas gastric cancer is usually a rapidly fatal disorder.

Taking our findings and the above considerations together, we believe subjects with a family history of noncardia gastric cancer should be offered noninvasive $\mathrm{H}$. pyl ori screening and eradication therapy if test results are positive. This policy will be particularly important in subjects with a strong family history of noncardia gastric cancer.

\section{References}

1. La Vecchia C, Negri E, Franceschi S, Gentile A. Family history and the risk of stomach and colorectal cancer. Cancer 1992;70:5055.

2. Graham S, Lilenfeld M. Genetic studies of gastric cancer in humans: an appraisal. Cancer 1958;11:945-958.

3. Zanghieri G, Di Gregorio C, Sacchetti C, Fante R, Sassatelli R, Cannizzo G, Carriero A, Deleon MP. Familial occurrence of gastric cancer in the 2-year experience of a population-based registry. Cancer 1990;66:2047-2051.

4. Ogawa H, Kato I, Tominaga S. Family history of cancer among cancer patients. J pn J Cancer Res 1985;76:113-118.

5. Cwern M, Garcia R, Davidson MI, Friedman IH. Simultaneous occurrence of gastric carcinoma in identical twins. Am J Gastroenterol 1981;75:41-47.

6. Nomura A, Stemmermann GN, Po-Huang C, Kato I, Perez-Perez GI, Blaser MJ. Helicobacter pylori infection and gastric carcinoma among Japanese Americans in Hawaii. N Engl J Med 1991;325: 1132-1136.

7. Parsonnet J, Friedman GD, Vandersteen DP, Chang Y, Vogelman $\mathrm{JH}$, Orentreich N, Sibley RK. Helicobacter pylori infection and the risk of gastric carcinoma. N Engl J Med 199;325:1127-1131.

8. Forman D, Newell DG, Fullerton F, Yarnell JWG, Stacey AR, Wald N, Sitas F. Association between infection with Helicobacter pylori and risk of gastric cancer: evidence from a prospective investigation. BMJ 1991;302:1302-1305.

9. Parsonnet J, Friedman GD, Orentreich N, Vogelman H. Risk for gastric cancer in people with CagA positive or CagA negative Helicobacter pylori infection. Gut 1997;40:297-301.

10. Kuipers EJ, Uyterlinda AM, Peria AS, Roosendaal R, Pals G, Nelis GF, Festen HPM, Meuwissen SGM. Long-term sequelae of Helicobacter pylori gastritis. Lancet 1995;345:1525-1527.

11. Sipponen P. Gastric cancer-a long-term consequence of Helicobacter pylori infection? Scand J Gastroenterol 1994;201:24-27.

12. Villako K, Kekki M, Maaroos HI, Sipponen P, Uibo R, Tammur R, Tamm A. Chronic gastritis: progression of inflammation and atrophy in a six-year endoscopic follow-up of a random sample of 142 Estonian Urban subjects. Scand J Gastroenterol 1991;186: 135-141.

13. Recavarren-Acre S, Leon-Baru R, Cok J, Berends on R, Gilman RH, Ramirez-Ramos A, Rodriguez C, Spira WM. Helicobacter pylori and progressive gastric pathology that predisposes to gastric cancer. Scand J Gastroenterol 1991;26(suppl 181):51-57.

14. El-Omar EM, Oien K, El-Nujumi A, Gillen D, Wirz A, Dahill S, Williams C, Ardill JES, McColl KEL. Helicobacter pylori infection and chronic gastric acid hyposecretion. Gastroenterology 1997; 113:15-24.

15. Correa P. A model for gastric cancer epidemiology. Lancet 1975;2:58-59.

16. Correa P. Human gastric carcinogenes is: a multistep and multifactorial process - first American Cancer Society Award lecture on cancer epidemiology and prevention. Cancer Res 1992;52:67356740.

17. Haruma K, Yoshihara M, Sumii K, Tari A, Watanabe C, Kodoi A,
Kajiyama G. Gastric acid secretion, serum pepsinogen I, and serum gastrin in Japanese with gastric hyperplastic polyps or polypoid-type early gastric carcinoma. Scand J Gastroenterol 1993;28:633-637.

18. Grossman MI, Kirsner JB, Gillespie IE. Basal and histalogstimulated gastric secretion in control subjects and in patients with peptic ulcer or gastric cancer. Gastroenterology 1963;45:1426.

19. Hitchcock $\mathrm{CR}$, Sullivan WA, Wangensteen $\mathrm{OH}$. The value of achlorhydria as a screening test for gastric cancer. Gastroenterology 1955;29:621-632.

20. Comfort MW. Gastric acidity before and after development of gastric cancer: its etiologic, diagnostic and prognostic significance. Ann Intern Med 1951;34:1331-1347.

21. Comfort MW, Kelsey MP, Berkson J. Gastric acidity before and after the development of carcinoma of the stomach. J Natl Cancer Inst 1947;7:367-373.

22. Mowat C, Murray L, Hilditch TE, Kelman A, Oien K, McColl KEL. Comparison of Helisal rapid blood test and ${ }^{14} \mathrm{C}$-urea breath test in determining Helicobacter pylori status and predicting ulcer disease in dyspeptic patients. Am J Gastroenterol 1998;93:20-25.

23. El-Nujumi A, Hilditch TE, Williams C, McColl KEL. Current or recent proton pump inhibitor therapy markedly impairs the accuracy of the ${ }^{14} \mathrm{C}$-urea breath test. Eur J Gastroenterol Hepatol 1998;10: 759-764.

24. Price $A B$. The Sydney system: histological division. J Gastroenterol Hepatol 1991;6:209-222.

25. Dixon MF, Genta RM, Yardley JH, Correa P. Classification and grading of gastritis: the updated Sydney system. Am J Surg Pathol 1996;20:1161-1181.

26. Genta RM. Recognising atrophy: another step toward a classification of gastritis. Am J Surg Pathol 1996;20(suppl 1):S23-S30.

27. Andrew A, Wyatt JI, Dixon MF. Observer variation in the assessment of chronic gastritis according to the Sydney system. Histopathology 1994;25:317-322.

28. Carneiro F, Taveira-Gomes A, Cabral-Correia A, VasconcelosTeixeira A, Barreira R, Cardoso-Oliveira M, Sobrinho-Simoes M. Characteristics of the gastric mucosa of direct relatives of patients with sporadic gastric carcinoma. Eur J Cancer Prev $1993 ; 2: 239-246$.

29. Kekki M, Siurala M, Ihamaki T. Enrichment of combined antral and corpus atrophic gastritis ("combined $\mathrm{AG}^{\text {") }}$ ) in sibs of gastric carcinoma patients. Scand J Gastroenterol 1991;26:24-28.

30. Kekki M, Ihamaki T, Varis K, Siurala M. Chronic gastritis profiles in sibs of probands calculated to carry a highly increased risk of gastric carcinoma. Scand J Gastroenterol 1991;26:29-32.

31. Levin AE, Kuchur BA. An investigation of the relatives of patients with gastric cancer. Lancet 1937;204-205.

32. Blaser MJ, Crabtree JE. CagA and the outcome of Helicobacter pylori infection. Am J Clin Pathol 1996;106:565-567.

33. Miehlke S, Genta RM, Graham DY, Go MF. Molecular relationships of Helicobacter pylori strains in a family with gastroduodenal disease. Am J Gastroenterol 1999;94:364-368.

34. Azuma $T$, Ito $S$, Sato $F$, Yamazaki $Y$, Miyaji $H$, Ito $Y$, Suto $H$, Kuriyama M, Kato T, Kohli Y. The role of the HLA-DQA1 gene in resistance to atrophic gastritis and gastric adenocarcinoma induced by Helicobacter pylori infection. Cancer 1998;82:10131018.

35. Lee A, Dixon MF, Danon SJ, Kuipers E, Mégraud F, Larsson H, Mellgard B. Local acid production and Helicobacter pylori: a unifying hypothesis of gastroduodenal disease. Eur J Gastroenterol Hepatol 1995;7:461-465.

36. Kuipers EJ, Uyterlinde AM, Pena AS, Hazenberg HJ A, Bloemena E, Lindeman J, Klinkenberg-Knol EC, Meuwissen SGM. Increase of Helicobacter pylori-associated corpus gastritis during acid suppressive therapy: implications for longterm safety. Am J Gastroenterol 1995;90:1401-1406. 
37. Stolte $M$, Meining A, Schmitz JM, Alexandridis T, Seifert E. Changes in Helicobacter pylori-induced gastritis in the antrum and corpus during 12 months of treatment with omeprazole and lansoprazole in patients with gastro-oesophageal reflux disease. Aliment Pharmacol Ther 1998;12:247-253.

38. Miller A B, Berrino F, Hill M, Pietinen P, Riboli E, Wahrendorf J. Diet in the aetiology of cancer: a review. Eur J Cancer 1994;30A: 207-220.

39. Buckley MJ M, O'Shea J, Grace A, English L, Keane C, Hours han D, O'M orain CA. A community-based study of epidemiology of Helicobacter pylori infection and as sociated asymptomatic gastroduodenal pathology. Eur J Gastroenterol Hepatol 1998;10:375-379.

40. Vaira D, Miglioli M, Mule $P$, Holton J, Menegatti M, Vergura $M$, Biasco G, Conte R, Logan RPH, Barbara L. Prevalence of peptic ulcer in Helicobacter pylori positive blood donors. Gut 1994;35: 309-312.

Received J une 14, 1999. Accepted September 14, 1999.

Address requests for reprints to: Kenneth E. L. McColl, M.D., University Department of Medicine and Therapeutics, Western Infirmary, Glasgow G11 6NT, Scotland. e-mail: K.E.L.McColl@ clinmed.gla.ac.uk; fax: (44) 141-339-2800.

Supported by a grant from the Acute Healthcare Committee of the Scottish Home and Health Department. Dr. El-Omar was a recipient of a European Helicobacter pylori Study Group Fellowship through the Digestive Disorders Foundation, UK.

\section{Blumer of Blumer's shelf}

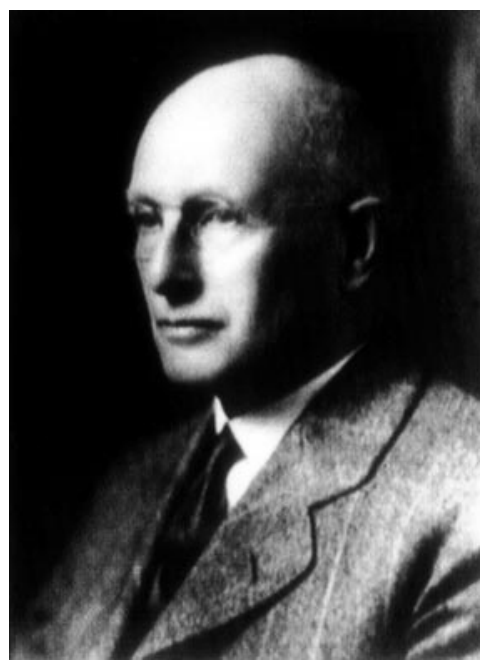

Copyright holder unknown. Photo obtained from the $\mathrm{N}$ ational Library of M edicine website (http://www. nlm.gov).
George Blumer (1872-1962) was born at Darlington, England, and at age 17 emigrated with his family to California where he matriculated at the Cooper Medical College in San Francisco (the forerunner of Stanford's medical school). Following a year of internship at the San Francisco County H ospital, he traveled to Baltimore where he served as house office in surgery under $\mathrm{H}$ alsted, then in medicine under O sler and as assistant in pathology under W elch. In 1896 he was appointed di rector of the Bender H ygienic Laboratory and professor of pathology at the Albany Medical College. From 1906 to 1920 he served as professor of medicine at Yale, the last 10 years as dean. A prolific writer, he authored a 3-volume text on bedside diagnosis. In 1909 he described the pal pable shelf, "a neglected rectal sign of value in the diagnosis and prognosis of obscure malignant and inflammatory disease within the abdomen." Gifted by wit and charm, he was esteemed as a consummate clinician. Scripps Clinic and Research F oundation, L a J olla, California 